\title{
Quem será o mais-um? Contribuições da psicanálise para o campo da política
}

\author{
Ana Carolina Borges Leão Martins
}

\begin{abstract}
Resumo
Quem será o mais-um? A pergunta que se repete a cada novo cartel constituído nos servirá de mote para discutir as contribuições da psicanálise para o campo da política. Em uma perspectiva lógica, investigaremos a distinção entre a política do Um, agenciada pela exceção, e as políticas do um a um, em estreita articulação com a função do mais-um. Descentralizadas, pluralizadas, singularizadas, as políticas do um a um nos remetem à possibilidade de fazer laço entre sujeitos dessemelhantes, tomados em suas inteiras singularidades. Sob tal perspectiva, se há um índice de "quem será o mais-um", ele se refere às chances de contar (com) a diferença no trabalho que se produzirá um a um. Nas conclusões, a dimensão política da função do mais-um será retomada em uma perspectiva mais ampla, do cartel à pólis, no debate das questões relacionadas com o governo e a diferença.
\end{abstract}

\section{Palavras-chave:}

Psicanálise; Política; Cartel, Mais-um.

\section{Who will be the plus one? Contributions of psychoanalysis to the field of politics}

\begin{abstract}
Who will be the plus one? The same question asked in each newly established cartel will serve as a motto to discuss the contributions of psychoanalysis to politics. From a logical perspective, we will investigate the distinction between the policy of the One, mediated by the exception, and the one to one policies, in close coordination with the function of the plus one. Decentralized, pluralized and singularized, one-to-one policies remind us of possible linkages among dissimilar subjects taken in their entire singularities. In such a perspective, any sign of "who the plus one will be" will refer to the odds of counting (on) difference, in the work
\end{abstract}


that will be produced one by one. In the conclusions, the political realm of the role of the plus one will be resumed in a broader perspective, from the cartel to the polis, in the debate on issues related to governance and difference.

\title{
Keywords:
}

Psychoanalysis; Politics; Cartel; Plus one.

\section{¿Quién será el más uno? Contribuciones del psicoanálisis al campo de la política}

\section{Resumen}

¿Quién será el más uno? La misma pregunta formulada en cada cártel recién establecido servirá como lema para discutir las contribuciones del psicoanálisis a la política. Desde una perspectiva lógica, investigaremos la distinción entre la política del Uno, mediada por la excepción, y las políticas del uno a uno, en estrecha coordinación con la función del otro. Las políticas descentralizadas, pluralizadas y singularizadas de uno-a-uno nos recuerdan los posibles vínculos entre sujetos diferentes tomados en su total singularidad. Bajo esa perspectiva, cualquier señal de "quién será el más uno" se referirá a las probabilidades de contar (en) la diferencia, en el trabajo que se producirá uno por uno. En las conclusiones, el ámbito político del papel del más uno se reanudará en una perspectiva más amplia, desde el cartel hasta la polis, en el debate sobre cuestiones relacionadas con la gobernanza y la diferencia.

\author{
Palabras clave: \\ Psicoanálisis; Política; Cartel; Más-uno.
}

\section{Qui sera le plus-un ? Contributions de la psychanalyse à la politique}

\begin{abstract}
Résumé
Qui sera le plus un ? Cette question, qui se pose à chaque cartel nouvellement établi, servira de guide pour discuter les contributions de la psychanalyse au domaine de la politique. D'un point de vue logique, nous étudierons la distinction entre la politique de l'Un, agencée par l'exception, et les politiques de l'un par un, en étroite articulation avec la fonction du plus-un. Décentralisées, pluralisées et singularisées, les politiques de l'un par un renvoient aux liens possibles entre des sujets différents, pris dans leur singularité. Dans une telle perspective, s'il y a un indice de "qui sera le
\end{abstract}


plus-un", il se réfère à la probabilité de compter (sur) la différence, dans le travail qui se produira un par un. La dimension politique de la fonction du plus-un sera reprise à partir d'une perspective plus large, du cartel à la polis, dans le débat concernant les questions liées au gouvernement et à la différence.

\section{Mots-clés :}

Psychanalyse ; Politique ; Cartel ; Plus-un.

\section{"Quem será o mais-um?"}

A pergunta se repete de um começo a outro, em cada novo cartel recém-constituído. Três a cinco pessoas se encontram em torno de um tema de trabalho e escolhem, ou por acordo, ou por sorteio, essa "mais uma” pessoa, cuja função proponho aqui investigar. Apesar da variedade de arranjos para designar um nome, a ser declarado como tal, resta ainda em suspenso aquilo que se refere à função, ao que os diversos "mais-um" podem operar internamente, na dinâmica particular de cada cartel. Desenvolverei a ideia de que tal operação é lógica, mas também política, dizendo respeito às possibilidades de fazer laço entre sujeitos dessemelhantes, seja no cartel, na Escola ou nos demais espaços da pólis.

Sobre o assunto, Lacan (1964/1981, p. 17) se mostrou bastante categórico, resumindo em poucas palavras o que se esperava do mais-um: "o mais-um é encarregado da seleção, da discussão e do destino a ser reservado ao trabalho de cada um". Entretanto, 12 anos depois, na jornada de cartéis da Escola Freudiana de Paris, a coincidência entre a função e o sujeito nomeado já não parecia tão evidente: "O mais alguma coisa é um lugar que está vazio" (Lacan, 1976/1981, p. 68), afirmou Maurice Alfandari; "É a pessoa imaginária que cada um traz" (Lacan, 1976/1981, p. 70), contrapôs Pierre Kahn; “É uma pessoa no grupo a quem a gente se dirige" (Lacan, 1976/1981, p. 72), acrescentou Laurence Bataille. Diante de tantos mais "uns", Lacan chegou mesmo a ponderar que se tratava de uma função propositadamente desconhecida, "[o mais-um] é sempre desconhecido porque isso é o Outro do Outro, esse mais-um está sempre presente, sob formas diferentes onde ele se encarna” (Lacan, 1976/1981, p. 73).

“Quem será o mais-um?" parece ser, portanto, uma pergunta sem resposta. Pois, mesmo que existam designações, mesmo que um nome ali se inscreva, restará sempre o problema do que a função opera singularmente, para cada um...

Tais considerações iniciais nos deixam advertidos quanto ao risco de fazer a tipologia dos "mais uns", recenseando a maneira pela qual esse ou aquele sujeito operou a função. Se assim fosse, produziríamos um indesejado deslocamento: o mais-um logo assumiria a consistência do "mas, Um”, conjunção adversativa índice do reinvestimento do lugar do Um, com todas as consequências morais 
desencadeadas pelos discursos ontológicos. Na contraposição, será preciso extrair - da experiência - a dimensão lógica e política envolvendo a função do mais-um, responsável por inscrever um modo de trabalho com a psicanálise, no campo institucional e mais além.

Dois tópicos serão dedicados a diferenciar a "política do Um" das "políticas do um a um". No primeiro, trataremos de três figuras solidárias à existência do Um, que consistem: na exceção, na massa e no excluído; no segundo, discutiremos outra vertente do Um: o Um inconsistente, o elemento unitário do conjunto vazio, em jogo nas políticas do um a um. Nas conclusões, a dimensão política da função do mais-um será retomada em uma perspectiva mais ampla: do cartel à pólis, discutiremos as questões envolvendo o governo e a diferença para apontar algumas contribuições da psicanálise ao campo da política.

\section{Três figuras do Um: a exceção, a massa, o excluído}

As elaborações teóricas de Freud e de Lacan nos possibilitam destacar três figuras do "Um", escrito assim mesmo, em maiúsculo, para bem demarcar o "Um" que faz conjunto, em uma perspectiva unificante. Lacan (1971-1972/2011) nos remete à distinção entre esse Um que faz conjunto, em que há um atributo comum partilhado, e o "um" que faz elemento, escrito em minúsculo, o "um" a "um" da diferença pura. De um lado, temos a função universalizante do Um, "que cai sob a influência do atributo" (p. 134); de outro, o "um como diferença pura, que distingue a noção de elemento" (p. 134), o qual apenas se contabiliza na singularidade. Nessa perspectiva, a exceção, a massa e o excluído são (con)figurações que se constituem, em termos lógicos, sob o agenciamento do Um universalizante. Iremos percorrê-las para nos aproximarmos de outra lógica, enodada pelo "um a um", muito mais próxima do funcionamento dos cartéis.

A primeira (e mais importante) figuração do Um se refere à exceção, lugar de origem, responsável por instituir a dimensão do "todo". Embora a exceção seja uma necessidade lógica, e não exatamente uma pessoa de "carne e osso", Freud (1921/1996) nos forneceu alguns exemplos de personagens que "encarnam" o lugar de exceção, caracterizados pela dissimetria e pela suficiência: Jesus Cristo, no caso da Igreja, o comandante-chefe, no caso do Exército, exemplos que o remetem, em última instância, à função do pai, mas não de qualquer pai: a exceção é o pai de pura potência, o dito "pai primevo", esse com acesso irrestrito ao gozo, escapando à lei comum da castração.

Ao empreender uma leitura lógica da psicologia das massas freudiana, Lacan (1971-1972/2011) indicou a necessária existência do “ao menos um”, lugar da exceção paterna, para que a castração se constituísse em um atributo comum partilhado, válido para todos: "a partir de que existe um, é a partir daí que todos os outros podem funcionar, é em referência a essa exceção, a este 'existe" (Lacan, 1971-1972/2011, p. 32). Sob tal lógica, o “ao menos um”, o lugar da exceção, seria 
o operador responsável por fundar a massa, segunda figuração do "Um", em que todos os membros serão "somados" na qualidade de "um a mais".

É nesse ponto que a concepção freudiana de "massa", ou de "civilização", ressurge inteiramente articulada à ideia de "justiça social”, da exigência de igualdade entre os membros, em que "ninguém deve querer salientar-se, todos devem ser o mesmo e ter o mesmo" (Freud, 1921/1996, p. 130). O laço entre os membros do grupo assim se torna possível sob a condição de que cada um "pague" com seu tanto de satisfação pulsional, sem quaisquer privilégios, sendo recompensado com uma igual parcela de amor por parte do líder, esse último tomado em posição de exceção.

No entanto, o poder de Eros, da libido, em fundar unidades cada vez maiores (sob a bênção da justiça social) esbarra em um grave problema, relativo à ambivalência própria aos laços libidinais. Freud (1921/1996) acertadamente constatou que a concepção de justiça social é profundamente frágil: o imperativo de que todos devem "ser o mesmo" e "ter o mesmo" requer que se demarque, de modo especular, o lugar daquele que "não é”/“não tem”, para onde serão endereçados o ódio e a destrutividade. Assim, se a massa se constitui pela vertente do amor e do sacrifício ao pai, ela não pode deixar de gerar um inevitável efeito de segregação, que direciona a vertente de ódio ao campo do outro. Chegamos, portanto, à terceira figuração do Um: o excluído, ou o "um a menos".

Onde quer que vigore a política do Um, a questão da diferença estará sempre muito mal posicionada. Se a exceção, a massa e o excluído aparentemente se mostram dissimétricos entre si, na dinâmica interna de cada um deles a diferença estará completamente escamoteada: na exceção, temos o "ao menos um" de pura suficiência, tomado como referência única para o todo; na massa, temos o "um a mais" que se soma initerruptamente, de forma homogênea; por fim, no excluído, os "um a menos" se apresentam indistintos, porque estão sempre referenciados ao círculo fechado da massa.

Esse mau posicionamento da diferença introduz importantes reflexões à política e ao laço social: nos atuais regimes democráticos, por exemplo, não é difícil constatar o quanto o horizonte do direito civil, fundado sob o ideal de igualdade, ejeta para fora de seu círculo o "não cidadão", o "não humano", esses "um a menos" que se tornam alvos fáceis da violência e do aniquilamento. Assim, o reconhecimento de "uns" no campo da coletividade, no espaço da pólis, parece sempre se fazer às custas do sacrifício de outros ("uns"), postos em posição de exclusão. Um bom exemplo disso é a polêmica em torno do "casamento gay", em que, como bem indicou Butler (2003, p. 226), "a esfera da aliança legítima é estabelecida graças à produção e intensificação das zonas de ilegitimidade”. Regulamentando o casamento gay, o Estado normatizou e reconheceu um modo de aliança, mas para isso tornando inteligível uma vasta pluralidade de parcerias, de enlaces entre sujeitos. 
Haveria, então, uma modalidade de laço social minimamente advertida quanto aos efeitos segregadores da política do Um? Haveria uma política que incluísse a diferença em sua dimensão mais radical?

Questões que tocam intimamente as políticas das instituições de psicanálise.

\section{O cartel e as políticas do "um a um"}

No âmbito das instituições de psicanálise, a política do Um engendra uma topologia esférica, responsável por delimitar muito claramente as fronteiras do dentro e do fora, do interno e do externo. O que aí se instaura é a incorporação continuada do novo ao campo do mesmo, conferindo progressiva consistência à massa e também ao excluído. Essa é uma situação que se repete sempre que a institucionalização da psicanálise assume uma forma rígida e burocratizada, impondo-se condições apriorísticas para o acesso de novos membros, quaisquer que sejam: a obrigatoriedade da participação em um “curso" teórico, a interferência sobre a escolha dos analistas, a estipulação de um tempo mínimo de supervisão para dar início à clínica "propriamente dita” etc. Essas e outras condições que não raro ganham a força de imperativos superegoicos, emanados diretamente daqueles que corporificam a exceção paterna.

Muito lucidamente, Lacan (1956/1998) denunciou a relação íntima entre a hierarquia da International Psychoanalytical Association (IPA), agenciada por "ao menos um" didata, e o estado de inércia teórica em que se encontrava a psicanálise na década de 1950. Como a política do Um não suporta o questionamento (trata-se de uma política do silêncio), ela inevitavelmente conduz ao efeito de reprodução via fac-símile, que abarca tanto as elaborações teóricas quanto a experiência clínica. O resultado é a manutenção coletiva do estado de ignorância (crassa), do não querer saber sobre o real em jogo na formação do analista.

Ora, é bem sabido que o risco de multiplicação do mesmo não é privilégio da IPA e ainda assombra as atuais instituições de psicanálise, inclusive as de tradição lacaniana. No entanto, se não é possível expurgar completamente o fantasma do Um, que pelo menos seja possível responder analiticamente a ele no justo instante em que se manifeste. Nesse ponto, o cartel parece ser um dispositivo privilegiado, porque viabiliza uma resposta analítica às figurações do Um ao apontar para as políticas do "um a um".

$\mathrm{Na}$ contraposição da topologia esférica, com um dentro/fora bem-demarcados, o cartel se faz "cardo", dobradiça entre a Escola e quem quer que dela tenha o interesse de se aproximar. De fato, ao propor o cartel como uma das formas de ingresso de novos membros, Lacan (1980/1981) deslocou o efeito de reprodução coletiva, em que a diferença seria reintegrada à mesmidade, em direção à produção singular: "quatro se escolhem para levar a cabo um trabalho que deve ter um produto. Preciso: um produto próprio de cada um, e não coletivo" (Laca, 1980/1981, p. 51). Para além, a invenção lacaniana do cartel constituiu-se em um dispositivo de 
sustentação do campo analítico, essencial para movimentar o trabalho para com a psicanálise: "a Causa Freudiana não é Escola, e sim Campo - onde cada um terá liberdade para demonstrar o que faz com o saber que a experiência decanta" (Lacan, 1980/1981, p. 50).

Mas, para que cada um deposite seu saber particular, decantado pela experiência, uma condição lógica precisa ser satisfeita: ela se refere ao esvaziamento do lugar da exceção, do lugar do Um que faz conjunto. Sobre esse ponto, Lacan (1971-1972/2011) foi bastante incisivo em afirmar que há do Um (em francês: Y a de l'un), preservando, no entanto, o cuidado de distinguir a diferença entre "Uns": há o Um que existe como consistência, atributo partilhado por todos os elementos (do conjunto), e há do Um que existe como falta, o elemento unitário do conjunto vazio. Como vemos, tal distinção não é apenas lógica, mas também política, correspondendo a dois modos distintos de fazer laço entre (ím)pares.

De um lado, a política do Um inscreve o existente, o "ao menos um" que se impõe como causa discursiva, posto na origem da massa e do excluído. De outro, as políticas do um a um inscrevem o inexistente, o conjunto vazio responsável por descompletar o "todo", cuja consequência será o engendramento de uma pluralidade de "uns" desencarrilhados, capazes de se enodar, porém sem fazer conjunto, "não-todamente", por assim dizer. Esse Um que se deixa esvaziar, o Um que se inscreve na modesta qualidade do inexistente, supomos que ele tenha um nome: chama-se mais-um.

Essa concepção do mais-um, atrelada à inscrição do Um esvaziado, traz-nos a vantagem de nos prevenir contra o estabelecimento de qualquer normatividade para o trabalho entre analistas, em que seriam prescritas regras para o bom funcionamento. São tantos mais-um quantos forem os cartéis constituídos, em uma multiplicidade de políticas do um a um, (não-)todas refratárias à universalização. Mais ainda, é justamente a operatividade do lugar vazio que autoriza o endereçamento subjetivo àquele "encarregado da seleção, da discussão e do destino a ser reservado ao trabalho de cada um” (Lacan, 1964/1981, p. 17). De tal modo, se há um índice de "quem será o mais-um?", ele se refere às chances de contar (com) a diferença em sua inteira radicalidade, no trabalho que se produz um a um.

Descentradas, pluralizadas, singularizadas, as políticas do um a um assim se tornam um convite para discutir dois pontos de suma importância ao atual debate político: o governo e a diferença.

\section{Do cartel à pólis: governo e diferença}

As políticas do um a um parecem se ajustar muito bem à restrita matemática lacaniana dos cartéis, que só contabiliza de três a cinco, sendo quatro mais um a sua justa medida. Mas será preciso interrogar a viabilidade de uma política que conte (com) a diferença em laços sociais mais amplos, do cartel à pólis. A pergunta se refere à inscrição da função do mais-um no âmbito da macropolítica das 
instituições públicas ou privadas, esses variados espaços em que um psicanalista se insere: rede de educação, rede de saúde, universidades etc. Mas também se trata de uma pergunta sobre a implicação de (mais) um psicanalista na pólis, no horizonte dos problemas sociais que constituem as subjetividades de nosso tempo. Seria possível, então, posicionar-se politicamente em coerência com os princípios que atravessam a experiência analítica? Se "o inconsciente é a política”, conforme indicou Lacan (1966-1967), o que seria uma (macro)política que levasse em conta a radicalidade do inconsciente?

Nós não conhecemos ainda outra forma de governo da coisa pública que não seja orientada pela política do Um. Em maior ou menor medida, os regimes (ditos) democráticos hoje existentes estão amplamente fundados sob a lógica da exceção, em que, pela via do processo eleitoral, os "ao menos um" ressurgem na qualidade de representantes do povo, da massa, dos "um a mais" tomados como unidade homogênea e não conflitiva. Situação que apenas engorda o círculo dos "um a menos", dos sujeitos excluídos, abjetos, os que não se sentem contemplados pela lógica representativa.

As constantes crises dos regimes democráticos acirram ainda mais o abismo entre a exceção e a massa, em graus variados de ruptura da representatividade, que vão do autoritarismo aos regimes totalitários. Diante desse quadro, talvez fosse possível pensar na ampliação dos limites da representatividade como uma alternativa às ondas segregatórias internas à lógica democrática. Infelizmente, essa operação de incluir o excluído na inteligibilidade civilizatória das massas não deixa de produzir seus próprios excessos, os "uns" que, na qualidade de $s u$ plément, permanecem incontáveis, irrepresentáveis.

Os impasses da política do Um, no âmbito dos governos representativos, parecem, portanto, convergir para um mesmo ponto: a necessidade lógica de postular um sujeito (de exceção) como causa da ação política, esse "agente por detrás do ato", que J. Butler (2016) tão lucidamente criticou a propósito do raciocínio fundacionista das políticas de identidade. Encontramos aqui a máxima consistência do "ao menos um", em seu caráter ontológico e universalizante: o negro como agente das políticas raciais, a mulher acionando as políticas femininas, o homossexual na causa das políticas gays e - por que não? - o psicanalista como fundamento da causa analítica. Que a universalidade do sujeito de exceção falhe em dar conta das múltiplas e singulares experiências subjetivas, isso é incontestável. Resta ainda o problema se seria possível zerar a causa da ação política sem, com isso, destruir a própria política.

Nossa investigação sobre a função do mais-um nos indicou um modo de operar com o lugar da exceção, esvaziando-o, processo que resulta em um "efeito sujeito", na proliferação desses "uns" desencadeados. Vemos, portanto, que as políticas do um a um não ultrapassam, muito menos substituem, a política do Um: se assim fosse, teríamos uma prescrição de governabilidade, espécie de utopia psi- 
canalítica. No avesso da prescrição, as contribuições da psicanálise ao campo da política antes nos ensinam a reposicionar a função da causa: do desejo de uma causa à causa do desejo.

Se o desejo de uma causa movimenta o discurso da militância, instituindo uma visada em comum para a massa, a causa do desejo movimenta o discurso analítico, que apenas reconhece um único sujeito de exceção: o inconsciente. Há, portanto, um sujeito que se constitui em consequência da ação política da psicanálise, jamais em anterioridade a ela. O inconsciente, próprio a cada um, remete-nos à dimensão radical da exceção, antes da ordem da insistência que da existência, que apenas no a posteriori da experiência analítica revela sua função de causa, de determinação subjetiva.

As políticas do um a um nos parecem, portanto, orientadas pelo desejo de encontro com a radicalidade da exceção ou, em outros termos, pelo "desejo de obter a diferença absoluta" (Lacan, 1964/1998, p. 260), como Lacan nomeou o desejo do analista. Parafraseando Lacan (1964/1998), o estatuto do mais-um é ético, e não ôntico; ele se refere à instauração do vazio como elemento comum a todos os elementos de um mesmo conjunto, esse elo que enlaça sujeitos dessemelhantes, tomados em suas diferenças absolutas.

Como bem indicou Freud (1937/1996), é a relação com o impossível que está em causa tanto no governar quanto no psicanalisar. Talvez as questões levantadas por nosso trabalho tenham duplicado esse encontro com o impossível ao nos remeterem às articulações entre o discurso analítico e a governabilidade. Como resto de tal articulação, permanece a aposta na inscrição da diferença, do cartel à pólis. 


\section{Referências bibliográficas}

Butler, J. (2003). O parentesco é sempre tido como heterossexual? Cadernos Pagu (21), 219-260). Recuperado de http://www.scielo.br/pdf/\%0D/cpa/n21/n21a10.pdf Butler, J. (2016). Problemas de gênero: feminismo e subversão da identidade (Renato Aguiar, Trad.). Rio de Janeiro: Civilização Brasileira.

Freud, S. (1921/1996). Psicologia de grupo e análise do ego (Jayme Salomão, Trad.). In J. Strachey (Ed.). Edição standard brasileira das obras psicológicas completas de Sigmund Freud (Vol. 13, pp. 77-155). Rio de Janeiro: Imago.

Freud, S. (1937/1996). Análise terminável e interminável (Jayme Salomão, Trad.). In J. Strachey (Ed.). Edição standard brasileira das obras psicológicas completas de Sigmund Freud (Vol. 23, pp. 223-271). Rio de Janeiro: Imago.

Lacan, J. (1956/1998). Situação da psicanálise e formação do analista em 1956. In J. Lacan. Escritos (Vera Ribeiro, Trad.) (pp. 461-495). Rio de Janeiro: Jorge Zahar. Lacan, J. (1964/1981). Ata de fundação. In J. Lacan. Documentos para uma Escola I, I (0). Documento de circulação interna da Letra Freudiana - Escola, Psicanálise e Transmissão. Rio de Janeiro.

Lacan, J. (1964/1998). O seminário, livro 11: os quatro conceitos da psicanálise (MD Magno, Trad.). Rio de Janeiro: Jorge Zahar.

Lacan, J. (1966-1967). O seminário, livro 14: a lógica da fantasia. Recife: Centro de Estudos Freudianos do Recife. Publicação não comercial.

Lacan, J. (1971-1972/2011). ...Ou pior. Publicação não comercial, exclusiva para os membros do Espaço Moebius.

Lacan, J. (1976/1981). A função dos cartéis. In J. Lacan. Documentos para uma Escola I, I (0). Documento de circulação interna da Letra Freudiana - Escola, Psicanálise e Transmissão. Rio de Janeiro.

Lacan, J. (1980/1981). D’écolage. In J. Lacan. Documentos para uma Escola I, I (0). Documento de circulação interna da Letra Freudiana - Escola, Psicanálise e Transmissão. Rio de Janeiro.

Recebido: 15/04/2018

Aprovado: 21/05/2018 